\title{
A INFLUÊNCIA DOS FATORES GEOECOLÓGICOS E GEOURBANOS NO CLIMA URBANO DE IPORÁ-GO: UMA ANÁLISE A PARTIR DOS MÉTODOS DE CORRELAÇÃO E REGRESSÃO LINEAR
}

\author{
Washington Silva Alves - washiipora@hotmail.com \\ Mestre em Geografia - Profo da Universidade Estadual de Goiás - Campus de Iporá \\ Zilda de Fátima Mariano - zildadefatimamariano@gmail.com \\ Doutora em Geografia - Profa da Universidade Federal de Goiás - Campus de Jataí
}

\begin{abstract}
RESUMO: O objetivo desse trabalho consistiu em analisar a influência dos fatores geoecológicos e geourbanos no padrão da temperatura do ar máxima e mínima absoluta em Iporá-GO, por meio dos métodos estatísticos de correlação e regressão linear. Os fundamentos teóricos e metodológicos pautaram-se no sistema clima urbano de Monteiro (2003), com ênfase no subsistema termodinâmico. Os fatores geoecológicos (hipsometria, exposição de vertente, vegetação urbana e hidrografia) e geourbanos (densidade de construção e o uso do solo urbano), foram georreferenciado com auxílio dos softwares ArcGis 9.0, Spring 5.3 e Surfer 9.0. Os dados de temperatura do ar foram coletados entre outubro de 2012 e outubro de 2013, em intervalos de 30 minutos, com termohigrômetros (modelo HT-500) e estações meteorológicas automáticas distribuídos em seis pontos da área urbana e rural de Iporá. Posteriormente, os dados foram organizados em planilhas de cálculos para análise estatística. Os resultados demonstraram que os fatores geoecológicos e geourbanos citados foram decisivos na variação espacial da temperatura do ar máxima e mínima absoluta em Iporá.
\end{abstract}

Palavras-chave: Climatologia, Cidade, Clima Urbano

THE INFLUENCE OF FACTORS AND GEOECOLOGICAL GEOURBANOS IN THE URBAN CLIMATE IN IPORÁ-GO: AN ANALYSIS FROM THE CORRELATION METHODS AND LINEAR REGRESSION

ABSTRACT: The objective of this study is to analyze the influence of geoecological factors and geourbanos the standard maximum air temperature and absolute minimum in Iporá-GO, by means of statistical methods of correlation and linear regression. The theoretical and methodological foundations guided in the urban climate system Monteiro (2003), with emphasis on thermodynamic subsystem. The geoecological factors (hipsometria, slop exposure, urban and Hydrography vegetation) and geourban (building density and the use of urban land), were georeferenced with the help of software ArcGIS 9.0, Sprint 5.3 and Surfer 9.0. The air temperature data were collected between October 2012 and October 2013, in 30-minute intervals, with hygrometer term (HT-500 model) and automatic weather stations distributed in six points of the urban and rural Iporá. Later, the data were organized into spreadsheets for statistical analysis. The results showed that geoecological mentioned factors and geourbanos were decisive in the spatial variation of the temperature of the air and maximum absolute minimum in Iporá.

Key words: Climatology, City, Urban Climate 


\section{INTRODUÇÃO}

No Brasil, a partir da década de 1960, o desenvolvimento técnicocientífico e informacional, aliado à mecanização do campo e aos pacotes tecnológicos herdados da revolução verde, atribuiu novas funções à cidade e ao campo. Esses fatores contribuíram para o aumento do êxodo rural, que, por sua vez, promoveu uma elevação nas taxas de urbanização.

De acordo com Santos (1996) na década de 1940 a taxa de urbanização era de 26,35\%, já na década de 1980 alcançou 68,46\%. Isso demonstrou que em quarenta anos a população urbana triplicou.

O crescimento acelerado da população urbana aliado a falta de planejamento desencadeou nas cidades problemas de ordem social e ambiental.

A cidade se tornou uma das manifestações mais clara da ação antrópica no meio ambiente, ação que transforma a paisagem natural, mudando a morfologia do terreno, modificando as condições climáticas e ambientais, cujos resultados são a degradação ambiental e a geração de um clima específico dos centros urbanos (LOMBARDO, 1985).

Portanto, este trabalho é fruto de uma pesquisa de mestrado desenvolvida na cidade de Iporá-GO, cujo objetivo consistiu em analisar a variação da temperatura e umidade relativa do ar, máximas e mínimas absolutas, em uma cidade de pequeno porte do cerrado brasileiro, identificando as relações com os aspectos físicos do ambiente, função e morfologia urbana.

Porém, neste trabalho será demonstrado a influência que os fatores geourbanos e geoambientais exercem na variação espacial da temperatura do ar máxima e mínima absoluta em Iporá, por meio dos métodos estatísticos de correlação e regressão linear.

\section{Fatores geoecológicos e geourbanos}

Os fatores geoecológicos e geourbanos estão ligados diretamente as características físicas do ambiente que a cidade foi construída, quanto as suas características morfológicas e funcionais. Portanto, se tratando de cidade de pequeno porte, como fatores geoecológicos podem ser citados: Hipsometria, Exposição de Vertentes, Declividade, Vegetação, e Hidrografia e como fatores geourbanos: Densidade de construção, de pavimentação, Uso e ocupação do solo, A estrutura urbana e Densidade do movimento de veículos e pessoas.

Monteiro (1990) definiu que qualquer análise preliminar para o estudo do clima urbano requer uma apurada investigação da tipologia do sítio, dos modelos de morfologia urbana e as diversas combinações que se podem configurar.

Essas características apresentam padrões diferenciados que variam de acordo com a expressão territorial da cidade e produzem características intraurbanas distintas de uma cidade para outra.

Para Mendonça (2003) as condições climáticas intraurbanas são derivadas da heterogeneidade tanto do sítio, quanto da estruturação, morfologia e funcionalidade urbana, que produzem, paralelamente ao clima da cidade (clima local/urbano), bolsões climáticos intraurbanos diferenciados (ilha de calor, frescor, topoclimas e microclimas).

Neste sentido Amorim (2010) declarou que além das diferenças de temperatura e umidade existentes entre a cidade e o campo é de fundamental 
importância compreender os mecanismos que promovem as diferenças existentes no interior das áreas urbanas que interferem negativamente na qualidade de vida das pessoas

Contudo, não dá para estudar o clima urbano sem associar os fatores geoecológicos e as características socioeconômicas da cidade.

Para essa pesquisa foram analisados os fatores geoecológicos (hipsometria, exposição de vertentes, hidrografia e vegetação urbana) e os fatores geourbanos (densidade de construção e o uso e ocupação do solo)

Relevo e exposição das vertentes

Geiger (1980, p. 382) destacou que "o clima das encostas, ou clima das exposições, é determinado, em primeiro lugar, porque as superfícies inclinadas recebem da radiação solar direta mais ou menos calor do que as superfícies horizontais".

Para Mendonça (1995, p. 50) "no caso do Hemisfério Sul, as faces de vertentes posicionadas à norte, noroeste, nordeste, oeste e leste recebem mais energia calorífico-luminosa do que aquelas voltadas a outras direções".

Romero (2000) ratificou que pequenas modificações da orientação e de elevação do relevo podem provocar variações significativas dos elementos climáticos em lugares separados por pequenas distâncias. Neste sentido, para Costa (2009) o detalhamento da hipsometria, topografia e geomorfologia do sítio urbano é de grande importância, pois as diferenças de temperatura podem ser provocadas pela topografia e exposição das vertentes.

Vegetação e hidrografia

A vegetação urbana é representada por conjuntos arbóreos de diferentes origens e que desempenham diferentes papéis (MELLO FILHO, 1985 apud PIVETTA e SILVA FILHO, 2002).

Barbosa (2005) ratificou que a vegetação influencia essencialmente em quatro fatores climáticos: temperatura do ar, umidade do ar, radiação solar e velocidade do ar. Assim, a vegetação condiciona a criação de ambientes termicamente favoráveis à saúde, habitabilidade e uso dos espaços urbanos.

Pinheiro e Amorim (2007) destacaram que as áreas da cidade com maior concentração de áreas verdes, ou próximas a reservatórios d'água, propiciam o declínio da temperatura do ar. "A ausência de vegetação e espelhos de água nas cidades reduz a evaporação, sendo que a radiação solar que não é utilizada na evaporação é transferida para o aquecimento das ruas, edifícios e o ar da cidade" (LOMBARDO, 1985, p. 33).

Amorim (2010) e Gartland (2010) confirmaram que as áreas de vegetação refrescam a sua vizinhança de duas maneiras: a) a evapotranspiração converte a energia solar em água evaporada, ao invés de calor, mantendo a temperatura da vegetação e do ar mais baixa e b) promove sombras para a superfície, protegendo-a do calor do sol, mantendo-a mais fresca e reduzindo a temperatura de superfície.

Specian et al. (2013) investigou a variação de temperatura e umidade relativa do ar entre dois pontos da área urbana de Iporá-GO, um remanescente de cerrado e uma área urbanizada, e concluiu que o remanescente de cerrado 
contribuiu para menores valores de temperatura e maiores valores de umidade relativa do ar.

Densidade de construção e Uso do solo

Romero (2000) apontou que o solo impermeabilizado e drenado apresenta um albedo maior e uma menor condutibilidade, tornando o clima local instável e que, ao mesmo tempo, reduz a umidade e o efeito refrescante produzido pela evaporação da água do solo.

Para Fialho (2009), os materiais artificiais presentes nos ambientes urbanos dificultam a dissipação do calor armazenado durante o dia e contribui para que a área urbana seja mais quente que a área rural próxima durante o período noturno.

Para Costa (2009) os menores valores de umidade relativa do ar nas áreas urbanas, na maioria das vezes, estão associados a locais que apresentam solo impermeabilizado, com pouca vegetação, o que impede a infiltração e a evaporação da água presente nos solo.

Amorim (2010), em estudo realizado em Presidente Prudente-SP, identificou que os bairros com maior adensamento de construção apresentaram maiores valores de temperatura do ar em relação aos bairros com menor adensamento.

\section{Caracterização da área de estudo}

Iporá está localizada na mesorregião do Oeste Goiano e na microrregião de Iporá, entre as coordenadas $16^{\circ} 24^{\prime} 00^{\prime \prime}$ e $16^{\circ} 28^{\prime} 00^{\prime \prime} \mathrm{S}, 51^{\circ} 04^{\prime} 00^{\prime}$ e $51^{\circ}$ 09' 00" O, com população de 31.274 habitantes, segundo o IBGE (2010) (Figura $1)$.

O município de Iporá faz divisa territorial com sete municípios: Amorinópolis e Ivolândia, ao sul, Moiporá e Israelândia, a leste, Diorama e Jaupací, ao norte e Arenópolis a oeste, e está a $220 \mathrm{Km}$ da capital do estado de Goiás (Goiânia).

Segundo Gomis (1998) a ocupação da região de Iporá ocorreu durante o século XVIII, período do ciclo do ouro em Goiás, e tornou-se importante devido a dois fatores: a) a abundância de ouro e diamantes encontrados nos seus rios e b) sua localização na rota colonial, com acesso a Cuiabá-MT. 


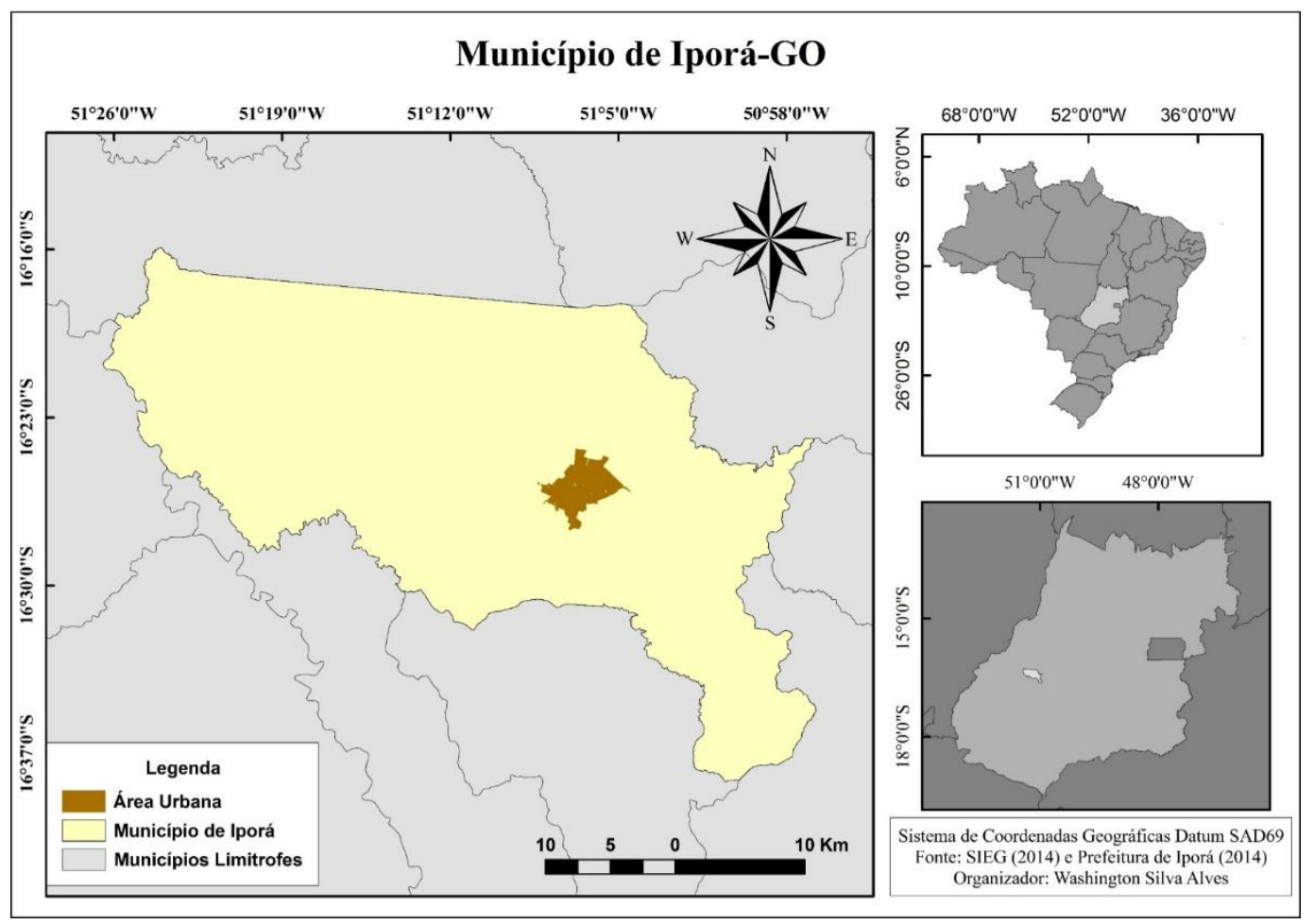

Figura 1: Localização da área de estudo Fonte: Org. do Autor (2014) e SIEG (2014)

Em 1949 a cidade de Iporá era um vilarejo pequeno, com vegetação nativa de cerrado em suas proximidades, porém, com a passar dos anos a paisagem urbana foi sendo modificada e novos mecanismos foram sendo implantados, a vegetação natural foi sendo suprimida para dar lugar a uma paisagem artificial constituída por concreto e pavimentação asfáltica, criando novas formas de uso e ocupação do solo urbano (Figura 2).

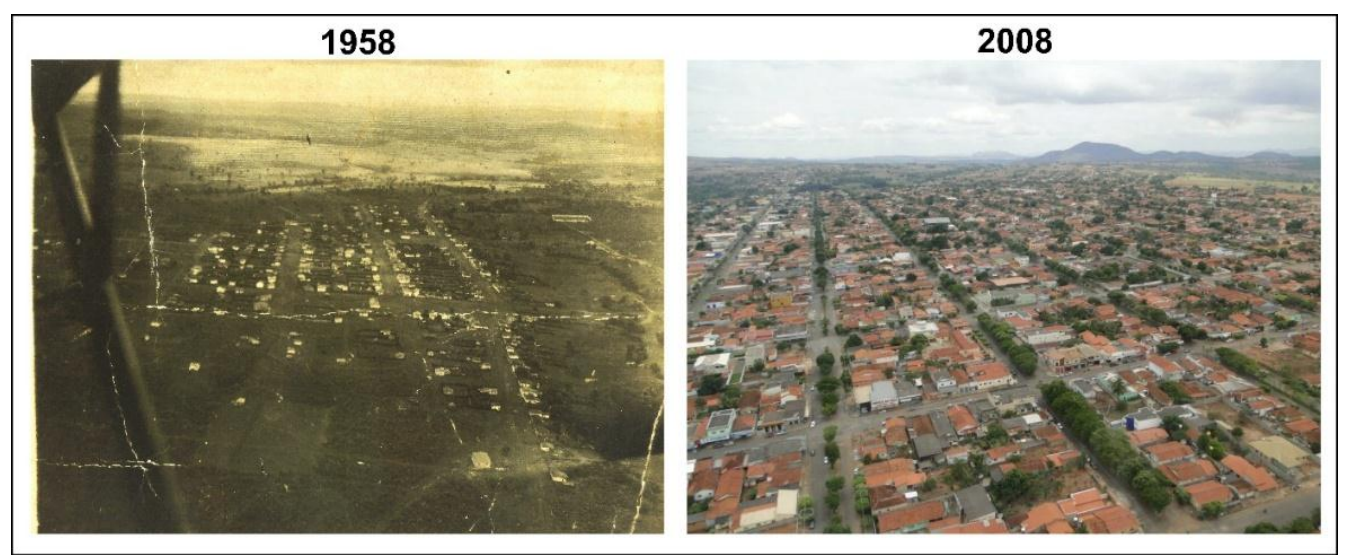

Figura 2 - Foto aérea de Iporá, em 1952 e em 2008

Fonte: Igreja Presbiteriana de Iporá (2004) e Polícia Militar $12^{\circ}$ BPM (2008) 
Atualmente, a população urbana de Iporá está distribuída em 66 bairros e o número de lotes e as taxas de ocupação variam de bairro para bairro; do total de lotes distribuídos pelos 66 bairros da cidade, apenas 51,5\% estão ocupados.

Em relação as características climáticas regionais, Iporá apresenta o tipo climático (Aw) (clima tropical de savanas com chuvas no verão), conforme a classificação de Koppen; para Torres e Machado (2011), esse tipo climático predomina nas áreas do Brasil central.

Sousa (2013) definiu que a cidade de Iporá apresenta temperaturas médias variando entre $24^{\circ} \mathrm{C}$ a $25^{\circ} \mathrm{C}$ e precipitação média de $1628 \mathrm{~mm} /$ ano, baseado nos dados de precipitação pluvial e de temperatura fornecidos pelo SIMEHGO (Sistema de Meteorologia e Hidrologia do Estado de Goiás) e pela ANA (Agência Nacional de Águas).

\section{MATERIAIS E MÉTODOS}

A proposta teórica e metodológica para esta pesquisa fundamentou-se no Sistema de Clima Urbano (S.C.U.), proposto por Monteiro (2003), com ênfase no canal termodinâmico.

Os fatores geoecológicos (hipsometria, exposição de vertente e vegetação urbana) e os fatores geourbanos (densidade de construção e o uso do solo urbano) foram mapeados por meio de softwares de geoprocessamento, ArcGis 9.0 e Spring 5.3 com o auxílio de imagens de satélites e do banco de dados da prefeitura municipal. Porém, nesse trabalho foram representados em um quadro síntese.

Os dados de temperatura do ar foram coletados no período de outubro de 2012 a outubro de 2013, por meio de estações automáticas e termohigrômetros (Data Loggers - Modelo HT-500) distribuídos em cinco pontos na área urbana (P2- Campus da UEG; P3- Secretaria Regional de Saúde; P4Vila Itajubá I; P5- Setor Central e P6- Bairro Mato Grosso) e em um ponto na área rural (P1- Chácara Pindaíba).

Antes de serem instalados os equipamentos foram calibrados e programados para registrar valores de temperatura e umidade relativa do ar em intervalo de 30 em 30 minutos, fato que tornou possível obter maior número de informações sobre o comportamento dos elementos climáticos analisados em diferentes pontos da cidade.

Os dados obtidos em campo foram armazenados em um banco de dados no software Excel e identificados os valores máximos e mínimos absolutos diários e mensais para definir o mês mais quente, mais frio, mais seco e mais úmido. Com base no tratamento estatístico dos dados, ficou definido como o mês mais quente (Outubro 2012), o mais frio (Julho 2013), o mais seco (Setembro 2012) e o mais úmido (Janeiro 2013).

Para analisar o índice de correlação existente entre os pontos de coleta distribuídos na área urbana de Iporá, foi elaborado um banco de dados em planilhas eletrônicas com os valores diários de temperatura máxima absoluta em outubro, temperatura mínima absoluta em julho, umidade máxima absoluta em janeiro e umidade mínima absoluta em setembro. 
Foi adotado o método do coeficiente de correlação linear de Pearson, definido por Figueiredo Filho e Silva Júnior (2009, p. 118) como "uma medida de associação linear entre variáveis", representado pela equação 1 .

$r=\frac{1}{n-1} \sum\left(\frac{x i-\bar{X}}{s x}\right)\left(\frac{y i-\bar{Y}}{s y}\right)$

$r=$ Coeficiente de correlação

$n$ = Tamanho da amostra

xi e yi = São as observações simultâneas das variáveis

$\mathrm{X}$ e $\mathrm{Y}=$ Médias aritméticas de cada uma das variáveis

Sx e Sy = Desvio padrão das amostras

O coeficiente de relação existente entre as variáveis analisadas é denominado por $(r)$ e indica o nível de correlação que existe, sendo definido por Crespo (2004) como: a) Positivo (se os pontos do diagrama apresentam como "imagem" uma reta ascendente); b) Negativo (se os pontos têm como "imagem" uma reta descendente) e c) Não linear (se os pontos têm como "imagem" uma curva).

Crespo (2004) definiu os valores de $r$ pertencentes ao intervalo de -1 e +1 , ou seja, se $(r)$ é igual a +1 , há uma correlação perfeita e positiva entre as variáveis, se $(r)$ for igual a - 1, há uma correlação perfeita negativa entre as variáveis, mas, se $(r)$ for igual a zero, ou não há correlação entre as variáveis ou a relação que existe não seja linear.

Os parâmetros para analisar a correlação linear entre duas variáveis foram definidas por Crespo (Op. Cit.), conforme o Quadro 1.

\begin{tabular}{|c|c|}
\hline Coeficiente de Correlação & Correlação \\
\hline $\mathrm{r}=1$ & Perfeita Positiva \\
\hline $0,8<\mathrm{ou}=\mathrm{r}<1$ & Forte Positiva \\
\hline $0,5<\mathrm{ou}=\mathrm{r}<0,8$ & Moderada Positiva \\
\hline $0,1<\mathrm{ou}=\mathrm{r}<0,5$ & Fraca Positiva \\
\hline $0<\mathrm{r}<0,1$ & Ínfima Positiva \\
\hline 0 & Nula \\
\hline$-0,1<\mathrm{r}<0$ & Ínfima Negativa \\
\hline$-0,5<\mathrm{r}<\mathrm{ou}=-0,1$ & Fraca Negativa \\
\hline$-0,8<\mathrm{r}<\mathrm{ou}=-0,5$ & Moderada Negativa \\
\hline$-1<\mathrm{r}<\mathrm{ou}=-0,8$ & Forte Negativa \\
\hline $\mathrm{r}=-1$ & Perfeita Negativa \\
\hline
\end{tabular}

Quadro 1 - Parâmetros para análise da correlação linear

Fonte: Alves (2013 adaptado de Crespo (2004)

Para Figueiredo Filho e Silva Júnior (2009), o certo é que, quanto mais perto de 1 (independente do sinal), maior é o grau de dependência estatística linear entre as variáveis; no outro oposto, quanto mais próximo de zero, menor é a força dessa relação.

Conforme Crespo (Op. Cit.), para melhor representar a correlação, os dados devem ser representados em diagramas de dispersão (os mesmos podem ser confeccionados por meio de softwares estatísticos). 
Seguindo a proposta do autor, foram construídos diagramas de dispersão, com o auxílio das ferramentas ("Gráficos" e "Dispersão"), disponíveis no menu "Inserir", do software Excel ${ }^{1} \mathrm{e}$, em seguida, foi traçada a linha de tendência e o valor do coeficiente de determinação $\left(R^{2}\right)$, através do menu "Layout" e da ferramenta "Linha de tendência".

Para analisar os sistemas atmosféricos predominantes em cada mês citado foi utilizado as imagens coloridas e de vapor de água do satélite GOES 13, disponibilizadas pelo Centro de Previsão do Tempo e Estudos Climáticos CPTEC e dos boletins agroclimatológicos do Instituto Nacional de Meteorologia INMET.

\section{RESULTADOS}

Os pontos de coletas apresentaram as seguintes características geoecológicas e geourbanas: a) P1(Chácara Pindaíba): Área rural, predomínio de vegetação nativa de cerrado e pastagens, vertente voltada para o sul e altitude de $565 \mathrm{~m}$; b) P2 (Campus da UEG): Área urbana, pouco construída, médio índice de vegetação, vertente voltada para oeste, uso de serviços e altitude de $602 \mathrm{~m}$; c) P3 (Secretaria regional de saúde): Área urbana, densamente construída, médio índice de vegetação, vertente voltada para o sul, uso residencial pavimentado e altitude de $576 \mathrm{~m}$;

d) P4 (Vila Itajubá I): Área urbana, densamente construída, baixo índice de vegetação, vertente voltada para noroeste, uso residencial pavimentado e altitude de $620 \mathrm{~m}$; e) P5 (Setor Central): Área urbana, densamente construída, médio índice de vegetação, vertente voltada para oeste, uso comercial, altitude de 602 m; f) P6 (Bairro Mato Grosso): Área urbana, densamente construída, alto índice de vegetação, vertente voltada para sudoeste, uso residencial pavimentado e altitude de $571 \mathrm{~m}$ (Figura 3 e Quadro 1).

\footnotetext{
${ }^{1}$ Marca registrada pela empresa proprietária, Microsoft.
} 


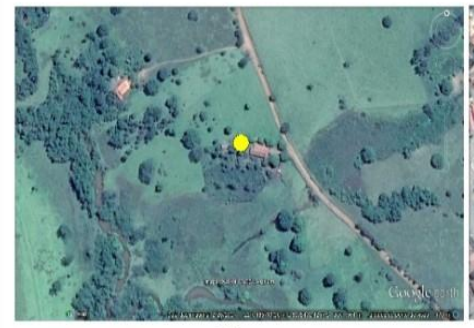

P1

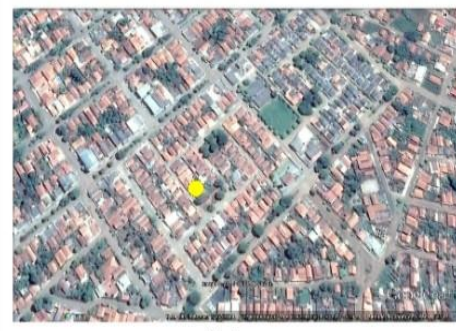

P4

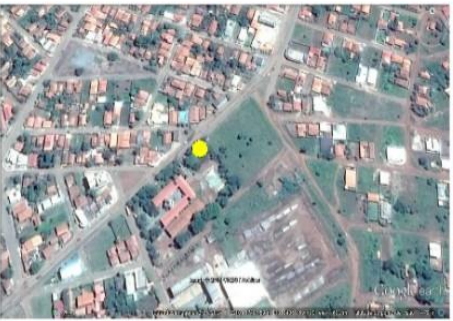

P2

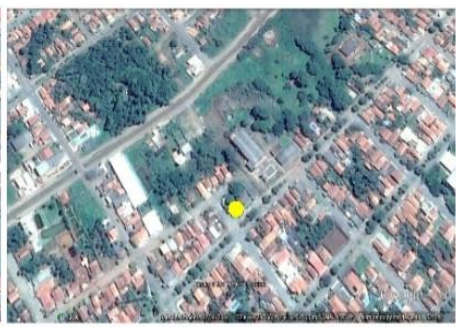

P3

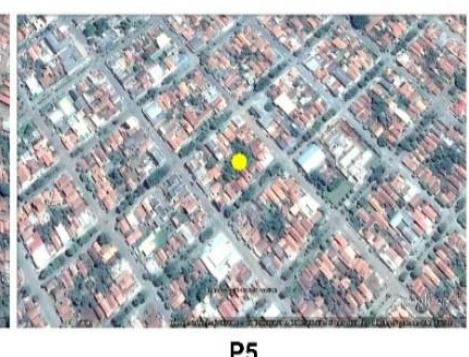

P5

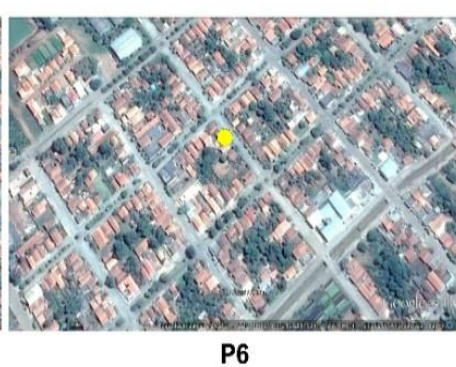

P6

Figura 3 - Pontos de coleta. Fonte: Google Earth (2014), Org. do Autor (2014) Quadro 1: Síntese dos aspectos geoecológicos e geourbanos analisados na cidade de Iporá-GO

\begin{tabular}{|c|c|c|c|c|c|}
\hline \multirow{2}{*}{ Pontos } & \multicolumn{2}{|c|}{ Fatores Geoecológicos } & \multicolumn{2}{c|}{ Fatores Geourbanos } \\
\cline { 2 - 6 } & $\begin{array}{c}\text { Hips. } \\
(\mathrm{m})\end{array}$ & $\begin{array}{c}\text { Exp. } \\
\text { Vertente }\end{array}$ & $\begin{array}{c}\text { Vegetação } \\
\text { urbana }\end{array}$ & $\begin{array}{c}\text { Densidade de } \\
\text { construção }\end{array}$ & Uso do solo \\
\hline P1 & 565 & Sul & Veg. Nativa & $0 \%$ & Pastagem \\
\hline P2 & 602 & Oeste & $(31-60 \%)$ & $<5 \%$ & $\begin{array}{c}\text { Uso de } \\
\text { Serviços }\end{array}$ \\
\hline P3 & 576 & Sul & $(31-60 \%)$ & $76-100 \%$ & $\begin{array}{c}\text { Resid. } \\
\text { Pavimentado }\end{array}$ \\
\hline P4 & 620 & Noroeste & $(0-30 \%)$ & $76-100 \%$ & $\begin{array}{c}\text { Resid. } \\
\text { Pavimentado }\end{array}$ \\
\hline P5 & 602 & Oeste & $(31-60 \%)$ & $76-100 \%$ & $\begin{array}{c}\text { Uso } \\
\text { Comercial }\end{array}$ \\
\hline P6 & 571 & Sudoeste & $(61-90 \%)$ & $76-100 \%$ & $\begin{array}{c}\text { Resid. } \\
\text { Pavimentado }\end{array}$ \\
\hline
\end{tabular}

Fonte: Org. do Autor (2014)

Em relação aos sistemas atmosféricos atuantes na região ficou demonstrado que durante o mês de outubro não houve eventos da Zona de Convergência do Atlântico Sul - ZCAS e predominou sobre o estado de Goiás uma massa de ar seco que dificultou a ocorrência de chuvas e elevou a temperatura do ar (INMET e CPTEC, 2012), (Figura 4).

No mês de julho, as frentes frias foram os sistemas atmosféricos que mais atuaram na região centro-oeste; o primeiro episódio foi registrado em 19/07 e o segundo e mais intenso, em 21/07, provocando quedas de temperatura e no dia 25 (INMET e CPTEC, 2013).

Neste período de atuação da frente fria, ocorreu a elevação do vapor de água na atmosfera sobre a região Centro-Oeste, em razão das características térmicas e higrométricas trazidas pela frente, provocando queda na temperatura (Figura 4). 


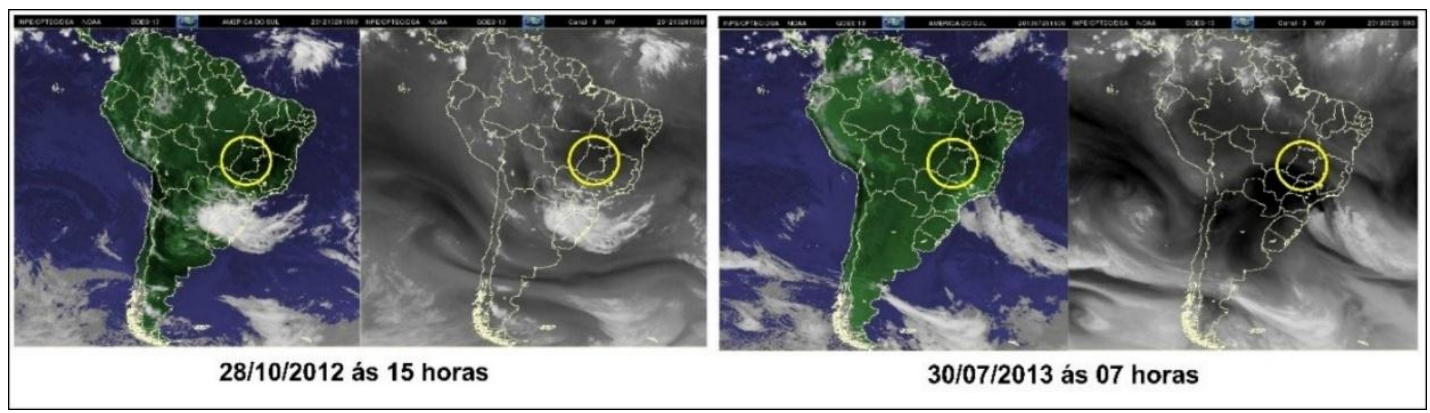

Figura 4 - Imagens colorida e de vapor de água na atmosfera do satélite Goes 13 Fonte: CPTEC (2014), Org. do Autor (2014)

Temperatura máxima absoluta em Outubro de 2012

No mês de outubro de 2012, as temperaturas máximas absolutas diárias ocorreram entre os horários das $12 \mathrm{~h} 30 \mathrm{~m}$ e $14 \mathrm{~h} 30 \mathrm{~m}$. O maior valor foi registrado no dia 28 ás $14 \mathrm{~h} 30 \mathrm{~min}$, no $\mathrm{P} 2\left(46,2^{\circ} \mathrm{C}\right)$, em condições de estabilidade atmosférica proporcionada pela atuação de uma massa de ar seco sobre Goiás.

Os valores diários de temperatura máxima absoluta de outubro (2012), registrados no $\mathrm{P} 2$, foram correlacionados com os valores obtidos pelos demais pontos para analisar o grau de correlação e a variação existente. O P2 foi escolhido como referência por que registrou com maior frequência os maiores valores máximos absolutos de temperatura.

O coeficiente de correlação ( $r$ ) revelou uma correlação positiva forte (maior que 0,8 ) do P2 com os demais pontos de coleta, ou seja, os valores de temperatura máxima absoluta registrados nos pontos P1, P3, P4, P5 e P6 estiveram próximo aos valores registrados pelo $\mathrm{P} 2$. Porém o coeficiente de determinação $\left(R^{2}=0,7342\right)$, resultante da correlação entre o P2 e P3, demonstrou que por influência do remanescente de cerrado e do córrego Tamanduá os valores de temperatura máxima absoluta, registrados no P3 foram menores e oscilaram menos que os valores obtidos no P2.

Isso indicou que a umidade proporcionada pelo processo de evapotranspiração da vegetação e pela evaporação da água do corpo hídrico amenizou os valores de temperatura, conforme foi demonstrado por Pinheiro e Amorim (2007).

Em contrapartida as características predominante na área do P2, (pouco construído com baixo índice de vegetação, com poucas ruas pavimentadas e a vertente voltada para oeste) contribuíram para maior variação dos valores de temperatura máxima absoluta obtidos no horário de 14h30min (Figura 5).

$\mathrm{Na}$ correlação entre o P2 e o P6 ficou evidenciado pelo coeficiente de determinação $\left(R^{2}=0,784\right)$ que os valores de temperatura máxima absoluta do ar registrados no P6 oscilaram menos que os valores registrados no P2, devido ao alto índice de vegetação e a posição da vertente voltada para o sul, que contribuiu para que os raios solares atingissem a superfície com menor intensidade durante o horário de 14h30min (Figura 5).

Portanto, ficou demonstrado estatisticamente que a densidade de construção, de vegetação, os corpos hídricos e a posição da vertente contribuíram para a menor variação dos valores de temperatura máxima absoluta do ar registrados pelo P3 e P6 em comparação aos valores do P2. 
A variação dos valores de temperatura máxima absoluta obtidos no P4 e P5 foi próxima a dos valores do P2, pois ao serem correlacionados com o P2 apresentaram coeficiente de determinação de $\left(R^{2}=0,8512\right)$ e $\left(R^{2}=0,8877\right)$ isto mostrou que a maior densidade de construção, pavimentação, o maior movimento de veículos e pessoas e as vertentes voltadas para noroeste e oeste atuaram para que essas áreas conservassem calor.

O mesmo ocorreu com o P1 onde o coeficiente de correlação foi de 0,8494 , porém foi a pastagem seca que contribuiu para elevação do albedo e influenciou na variação dos valores de temperatura máxima absoluta deixando-a próxima a variação encontrada no P2 ponto mais quente (Figura 5).

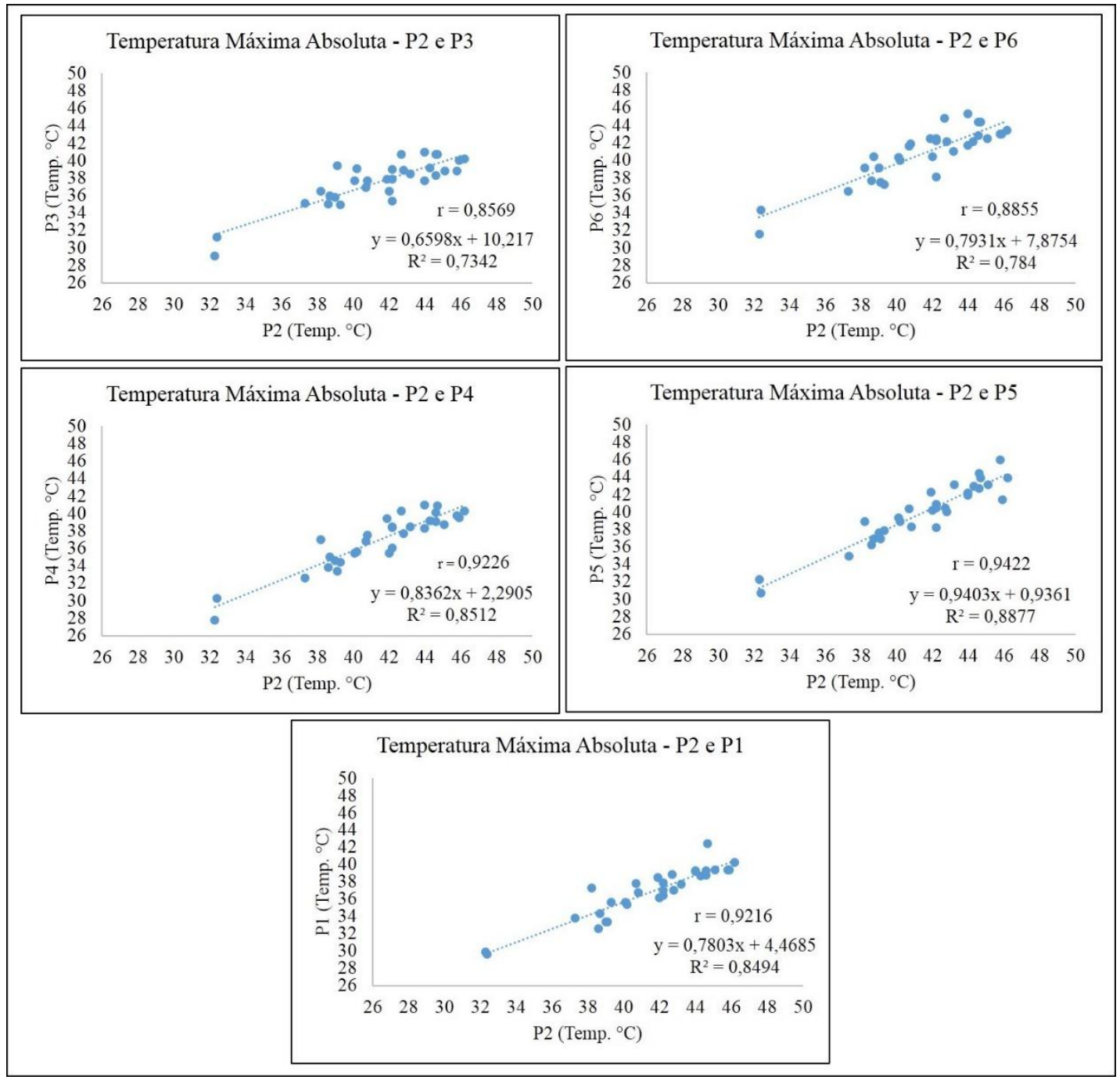

Figura 5 - Correlação dos valores de temperatura máxima absoluta obtidos no mês de outubro de 2012 entre o horário de $12 \mathrm{~h} 30 \mathrm{~min}$ e 14h30min, em Iporá-GO

Fonte: Org. do Autor (2014)

Temperatura mínima absoluta em Julho de 2013 
Embora os valores mínimos absolutos de temperatura tenham ocorridos com maior frequência no horário das $5 \mathrm{~h} 30 \mathrm{~m}$, o menor valor registrado foi às $7 \mathrm{~h}$, no P1 $\left(8,3^{\circ} \mathrm{C}\right)$, zona rural, no dia $30 / 07 / 2013$, sob atuação de uma massa de ar frio e seco sobre o estado de Goiás.

Neste mesmo dia e horário o P2 apresentou temperatura de $14,4^{\circ} \mathrm{C}, \mathrm{P} 3$ $\left(11,5^{\circ} \mathrm{C}\right), \mathrm{P} 4\left(19,7^{\circ} \mathrm{C}\right), \mathrm{P} 5\left(16,5^{\circ} \mathrm{C}\right)$ e $\mathrm{P} 6\left(18,0^{\circ} \mathrm{C}\right)$. Foi registrado uma amplitude de $11,4^{\circ} \mathrm{C}$ entre os pontos neste dia e horário, considerada muito forte, pois, conforme foi apontado por García (1996), as diferenças térmicas em uma cidade podem ser classificadas como muito forte quando são acima de $6^{\circ} \mathrm{C}$.

Os valores diários de temperatura mínima absoluta registrados no P1, durante o mês de julho de 2013 as $7 \mathrm{~h}$, foram correlacionados com os valores apresentados nos demais pontos. O P1 foi escolhido como como parâmetro para a correlação por ter registrado os menores valores absolutos de temperatura mínima.

O coeficiente de correlação $(r)$ revelou, estatisticamente, que os valores registrados pelo $\mathrm{P} 1$ apresentaram uma correlação moderada positiva com o P4 $(r=0,6371), P 5(r=0,6727), P 2(r=0,7701)$ e P6 $(r=0,7688)$ porém, com o P3, apresentou uma correlação positiva forte $(r=0,8925)$, ou seja, os valores de temperatura mínima absoluta registrados no P1 e P3 foram próximos (Figura $6)$.

O coeficiente de determinação entre o P1 e P3 $\left(R^{2}=0,7966\right)$ revelou que a vegetação do remanescente de cerrado e a proximidade com o córrego tamanduá, aturam para que os valores de temperatura máxima absoluta registrado no P3 apresentassem menor oscilação em relação aos valores registrados no $\mathrm{P} 1$, isso indicou que os valores registrados no $\mathrm{P} 3$ foram próximos aos valores registrados no P1 (Figura 6). Esse fato ocorreu em função do corpo hídrico e da vegetação do remanescente de cerrado próximos ao P3, que contribuíram para que os valores de umidade permanecesse constante, por meio do processo de evaporação da água e da evapotranspiração da vegetação.

Portanto, observou que a vegetação e o córrego tamanduá amenizaram os efeitos da urbanização, ou seja, reproduziram no interior do espaço urbano de Iporá condições térmicas próximas aquelas encontradas na zona rural no horário de 7 horas (Figura 6).

O coeficiente de determinação obtido entre a correlação do P1 e P2 ( $R^{2}$ $=0,5931), P 1$ e $P 4\left(R^{2}=0,4059\right)$, P1 e P5 $\left(R^{2}=0,4526\right)$ e P1 e P6 $\left(R^{2}=\right.$ $0,591)$ comprovou que os valores de temperatura mínima absoluta registrados nesses pontos variaram mais que os valores apresentados pelo P1, devido a densidade de construção, pavimentação, o baixo índice de vegetação e a posição das vertentes voltadas para oeste e noroeste. Essas características contribuíram para que a radiação solar incidida sobre a superfície dessas áreas desses pontos, permanecesse retida em forma de calor elevando a temperatura (Figura 6). 


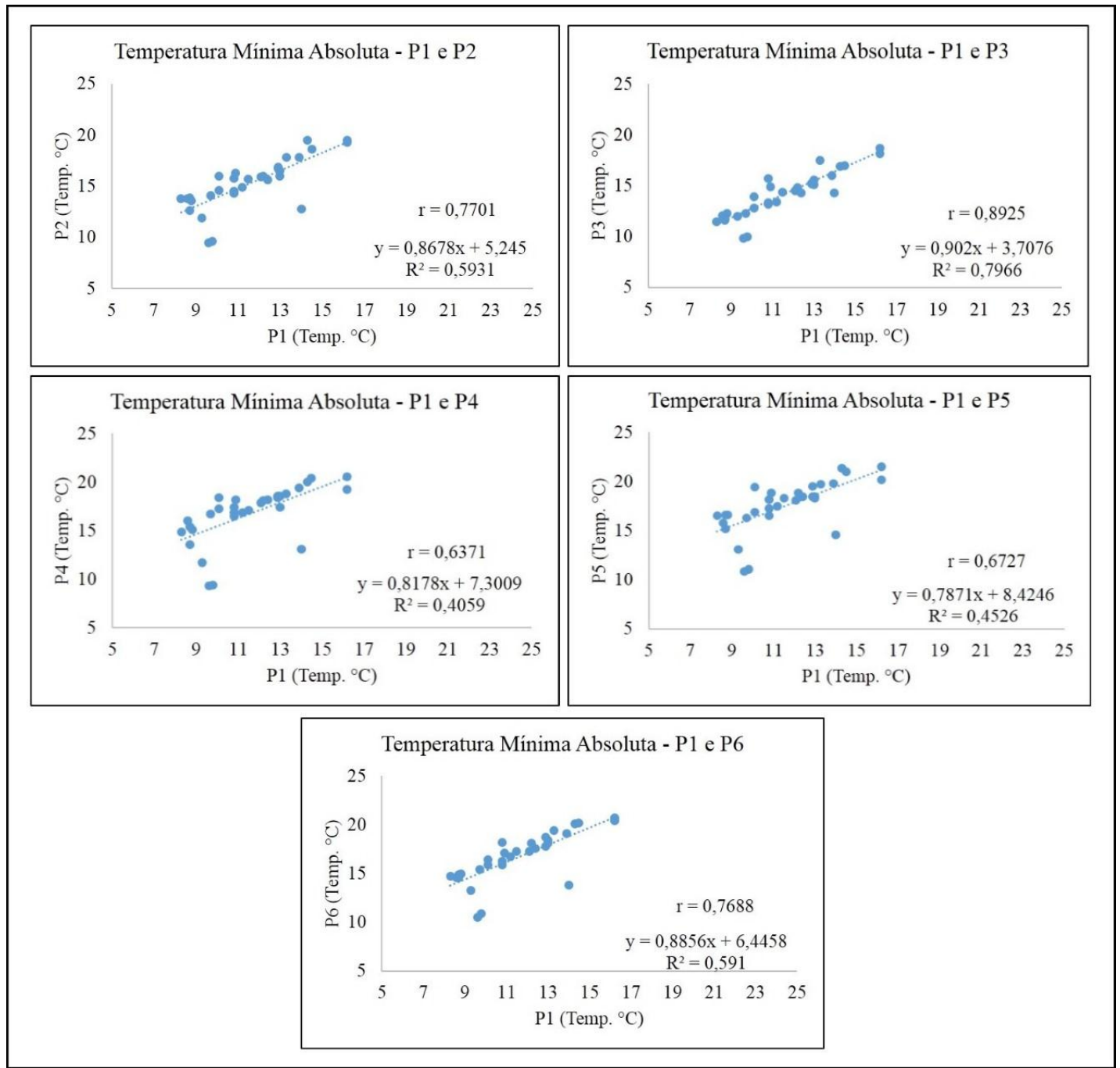

Figura 6 - Correlação dos valores de temperatura mínima absoluta obtidos no mês de julho de 2013 entre o horário de 5h30min e 7h, em Iporá-GO

Fonte: Org. do Autor (2014)

\section{CONSIDERAÇÕES FINAIS}

Considerando o período analisado, esse estudo demonstrou que o valor máximo e mínimo absoluto de temperatura do ar ocorreram nos meses de outubro de 2012 e julho de 2013, portanto ficaram caracterizados como o mês mais quente e o mês mais frio.

Os métodos estatísticos empregados na análise dos dados (correlação e regressão linear) demonstraram que as características geoecológicas e geourbanas da cidade de Iporá, influenciaram diretamente na variação da temperatura máxima e mínima absoluta. Vale destacar o papel do remanescente de cerrado e do córrego tamanduá que contribuíram para minimizar os efeitos da densidade de construção na área do P3, pois proporcionaram condições de 
temperatura máxima e mínima absoluta próximas dos valores registrados na área rural.

É importante ressaltar que a exposição das vertentes e a ausência de vegetação foram decisivas na variação dos valores de temperatura máxima absoluta do ar, porque durante o horário de maior insolação 14h30min o P2 área que apresentou essas características, registrou o valor máximo absoluto de temperatura, fato que contrariou a hipótese inicial de que o valor máximo absoluto de temperatura poderia ser encontrado na área central, onde a densidade de construção e o fluxo de veículos e pessoas é mais intenso.

\section{AGRADECIMENTOS}

Agradecemos a Fundação de Amparo à Pesquisa do Estado de Goiás FAPEG pelo auxílio financeiro durante a pesquisa e ao Laboratório de Climatologia da UFG - Campus Jataí por ter disponibilizado equipamentos que auxiliaram na coleta de dados.

\section{REFERENCIAS}

AMORIM, M. C. C. T. Climatologia e gestão do espaço urbano. Revista Mercator. Fortaleza - CE. 2010, p. 71 - 90. Disponível em: < http://www.mercator.ufc.br/index.php/mercator/article/view/534/299>. Acesso em: 21 maio. 2014.

BARBOSA, Ricardo Victor Rodrigues: Áreas verdes e qualidade térmica em ambientes urbanos: estudo em microclima de Maceió (AL). 2005. 135 p. Dissertação (Mestrado) - Escola de Engenharia de São Carlos - USP, 2005. Disponível em:

www.teses.usp.br/teses/disponiveis/18/18139/tde.../diss_Barbosa2005.pdf>. Acesso em: 21 Abr. 2014.

COSTA, Eduino Rodrigues da. O campo térmico-higrométrico intraurbano e a formação de ilhas de calor e de frescor urbanas em Santa Maria-RS. 2009. 114 p. Dissertação (Mestrado em Geografia) - UFSM-RS, Santa Maria-RS. 2009. Disponível em: <http://w3.ufsm.br/ppggeo/index2.php?option=com_docman\&task=doc_view\& gid=141\&Itemid=30>. Acesso em: 09 mai. 2014.

CPTEC. Centro de Previsão e Estudos Climáticos. 2013. Disponível em: < http://www.cptec.inpe.br/>. Acesso em: 28 Abr. 2014.

CRESPO, A. A. Correlação linear. In: CRESPO, A. A. Estatística fácil. 17 ed. São Paulo. Saraiva, 2004, p. 148 - 153.

FIALHO, E. S. Ilha de calor em cidade de pequeno porte: caso de Viçosa zona da mata mineira. 2009. 279 p. Tese (Doutorado em Geografia) - USP - SP, São Paulo. 2009. Disponível em: http://www.teses.usp.br/teses/disponiveis/8/8135/tde-22022010-154045/ptbr.php>. Acesso em: 15 abr. 2014. 
FIGUEIREDO FILHO, D. B.; SILVA JUNIOR, J. A. da. Desvendando os mistérios de correlação de Pearson. Revista Política Hoje. Recife-PE. 2009, n. 1, p. 115 146.

Disponível em:

http://www.revista.ufpe.br/politicahoje/index.php/politica/article/viewFile/6/6>. Acesso em: 16 mai. 2014.

GARCÍA, F. F. El clima urbano. In: Manual de climatología aplicada: clima, medio ambiente y planificación. Madrid: Editorial Sintesis, 1996. p. 253 278.

GARTLAND, L. O que é uma ilha de calor. In: Ilhas de calor: como mitigar zonas de calor em áreas urbanas. São Paulo: Oficina de Textos. 2010. p. 09-23.

GEIGER, R. Influências das formas do relevo no microclima. In:

Manual de microclimatologia: o clima da camada de ar junto ao solo. Lisboa: Fundação Caloust Gulbenkian. 1980. p. 382-474.

GOMIS, Moizeis Alexandre. Uma viagem no tempo de Pilões a Iporá (17481998). Goiânia, GO: Editora Nova Página, 1998.

IBGE. Instituto Brasileiro de Geografia e Estatística. IBGE cidades. Disponível em: < http://www.ibge.gov.br/cidadesat/xtras/perfil.php?codmun=521020>. Acesso em: 28 jun. 2014.

INMET. Instituto Nacional de Meteorologia 2013. Disponível em: < http://www.inmet.gov.br/>. Acesso em: 28 jun. 2014.

LOMBARDO, M. A. Ilhas de calor nas metrópoles: o exemplo de São Paulo. São Paulo: Hucitec, 1985.

MENDONÇA, F. Clima e planejamento urbano em Londrina: proposição metodológica e de intervenção urbana a partir do estudo do campo termohigrométrico. In: MONTEIRO, C. A. de F; MENDONÇA, F. A. Clima urbano. São Paulo: Contexto, 2003. p. 93 - 119.

MENDONÇA, F. de A. O clima e o planejamento urbano de cidades de porte médio e pequeno: proposição metodológica para o estudo e sua aplicação à cidade de Londrina/PR. 1995. 381 p. Tese (Doutorado em Geografia) - USP-SP, São Paulo. 1995. Disponível em: https://docs.google.com/file/d/OBxpb4dPwCfbJbjhPSFUxOWZ4eE0/edit?usp=sha ring $>$. Acesso em: 13 jan. 2014.

MONTEIRO, C. A. de F. M. Teoria e clima urbano: Um projeto e seus caminhos. In: MENDONÇA, F. A. Clima urbano. São Paulo: Contexto, 2003. p. 9 - 67.

MONTEIRO, C. A. F. Adentrar a cidade para tomar-lhe a temperatura. Geosul. Florianópolis-SC, 1990, n. 9, p. 61 - 79. 
PINHEIRO, G. M.; AMORIM, M. C. C. T. Uma contribuição ao estudo da temperatura e da umidade relativa do ar em Euclides da Cunha Paulista/SP. Revista Geografia em Atos. Presidente Prudente. 2007, n. 7, p. 58 - 70. 2007. Disponível em:

http://revista.fct.unesp.br/index.php/geografiaematos/article/viewFile/238/pdf1 6>. Acesso em: 22 abr. 2014.

PIVETTA, K. F. L.; SILVA FILHO, D. F. da. Boletim acadêmico: serie arborização urbana. Jaboticabal-SP. UNESP, 2002, p. 1-69.

ROMERO, M. A. B. Fatores climáticos locais. In: Princípios bioclimáticos para o desenho urbano. São Paulo: ProEditores, 2000, p. 30-36.

SANTOS, Milton. A urbanização brasileira. São Paulo: Hucitec, 1996.

SIEG. Sistema Estadual de Geoinformação. Mapas em pdf. 2014. Disponível em: < http://www.sieg.go.gov.br/>. Acesso em: 23 jun. 2014.

SOUSA, F. A. de. Caracterização física regional. In: A contribuição dos solos originados sobre granitos e rochas alcalinas na condutividade hidráulica, na recarga do lençol freático e na suscetibilidade erosiva: um estudo de caso na alta bacia hidrográfica do rio dos bois em Iporá-GO. 2013. 207 p. Teses (Doutorado em Geografia) - UFU-MG, Uberlândia, 2013.

SPECIAN, V; SILVA JUNIOR, U. P. da; VECHIA, F. A. da S. Padrão térmico e higrométrico para dois ambientes de estudo: área urbanizada e remanescente de cerrado na cidade de Iporá-GO. 2013. Disponível em: < file:///C:/Users/Washington/Downloads/206-680-1-PB.pdf $>$. Acesso em: 28 Abr. 2014.

TORRES, F. T. P.; MACHADO, P. J. de O. Introdução a climatologia: series textos básicos de Geografia. São Paulo-SP: Cengage, 2012. 